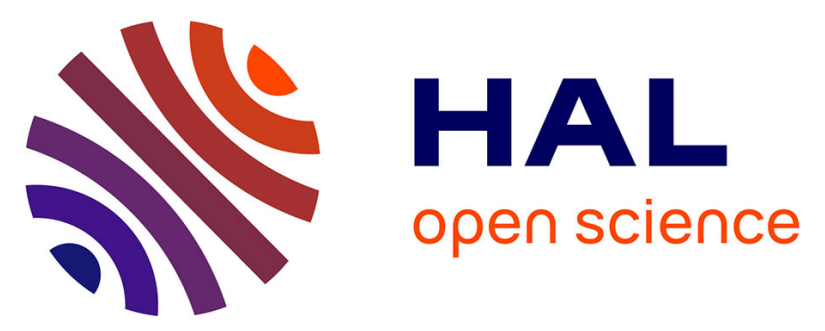

\title{
Uniform Generation of Sub-nanometer Silver Clusters in Zeolite Cages Exhibiting High Photocatalytic Activity under Visible Light
}

Mohamad El-Roz, Igor Telegeiev, Natalia Mordvinova, Oleg Lebedev, Nicolas Barrier, Asma Behilil, Moussa Zaarour, Louwanda Lakiss, Valentin Valtchev

\section{To cite this version:}

Mohamad El-Roz, Igor Telegeiev, Natalia Mordvinova, Oleg Lebedev, Nicolas Barrier, et al.. Uniform Generation of Sub-nanometer Silver Clusters in Zeolite Cages Exhibiting High Photocatalytic Activity under Visible Light. ACS Applied Materials \& Interfaces, 2018, 10 (34), pp.28702 - 28708. 10.1021/acsami.8b09634 . hal-01885083

\section{HAL Id: hal-01885083}

https://hal-normandie-univ.archives-ouvertes.fr/hal-01885083

Submitted on 5 Oct 2021

HAL is a multi-disciplinary open access archive for the deposit and dissemination of scientific research documents, whether they are published or not. The documents may come from teaching and research institutions in France or abroad, or from public or private research centers.
L'archive ouverte pluridisciplinaire HAL, est destinée au dépôt et à la diffusion de documents scientifiques de niveau recherche, publiés ou non, émanant des établissements d'enseignement et de recherche français ou étrangers, des laboratoires publics ou privés. 


\title{
Uniform Generation of Sub-nanometer Silver Clusters in Zeolite Cages Exhibiting High Photocatalytic Activity Under Visible Light
}

\author{
Mohamad El-Roz ${ }^{\dagger *}$ Igor Telegeiev, ${ }^{\dagger}$ Natalia E. Mordvinova, ${ }^{\S}$ Oleg I. Lebedev ${ }^{\S}$ Nicolas Barrier,${ }^{\S}$ Asma \\ Behlil, ${ }^{\dagger}$ Moussa Zaarour, ${ }^{\dagger}$ Louwanda Lakiss, ${ }^{\dagger}$ Valentin Valtchev ${ }^{\dagger *}$ \\ †Normandie Univ, ENSICAEN, UNICAEN, CNRS, Laboratoire Catalyse et Spectrochimie, 14050 Caen, France \\ ${ }^{\S}$ Normandie Univ, ENSICAEN, UNICAEN, CNRS, Laboratoire CRISMAT, 14050 Caen, France
}

\begin{abstract}
Sub-nanometer silver clusters that exhibit discrete electronic structure with molecular-like properties are highly desirable in various technologies. However, the methods for their preparation suffer from limitations related with the reproducibility and particles uniformity, and/or the possibility of the scaling-up. Another critical drawback is that free sub-nanometer silver clusters tend to aggregate into larger particles. In this work, a new approach that successfully overcomes the above limitations is developed. It allows, for the first time, an ultrafast preparation of sub-nanometer silver particles with high abundance, uniformity ( $7 \AA$ ) and stability into the cages of nanosized zeolite crystals. The new method consists in UV excitation of a water suspension of nano-zeolite containing photoactive vanadate clusters in the presence of ethanol (as an electron donor) and silver precursor. The characteristic features of sub-nanometer silver particles are presented and the mechanism of their formation is discussed. Sub-nanometer Ag clusters exhibit exceptional photocatalytic activity and selectivity in the reforming of formic acid to $\mathrm{H}_{2}$ and $\mathrm{CO}_{2}$ under visible light.
\end{abstract}

Keywords: Sub-nanoparticles, Silver clusters, Zeolite,

Photocatalysis, Formic acid reforming, H2

\section{Introduction}

It is well known that the properties of sub-nanometer silver clusters differ strongly from those of the bulk materials and conventional nanoparticles. ${ }^{1-4}$ Silver nanoparticles exhibit a significant surface plasmon resonance absorption due to a coherent oscillation of the conduction band electrons induced by light (electro-magnetic field). ${ }^{5}$ In contrast, sub-nanometeric silver clusters $(<1 \mathrm{~nm})$ show a discrete electronic structure with molecular-like properties (HOMO-LUMO gap). Thus, size-dependent fluorescence is often observed in the tiny metal clusters. ${ }^{3,6}$ Their unique electronic and optical properties render them potential candidates for application in various fields ranging from heterogeneous catalysis to biomedical application..$^{6-11}$ Metallic nanoparticles with size between 1-12 nm are widely used in catalysis. The control of their preparation at an atomic scale is crucial for tuning their properties. There is a continuous quest for developing highly efficient methods of size-selected metal clusters synthesis and their integration in appropriate solid carriers. However, the instability of the clusters due to their tendency to aggregate irreversibly into larger nanoparticles is a recurrent problem. The use of confining scaffolds, such as the regular system of cages in crystalline zeolite-type material, could be an efficient solution to overcome this problem. Silver-zeolite composites are often employed as catalysts, ${ }^{12}$ adsorbents,${ }^{13}$ molecular sieves, ${ }^{14}$ and recently as highly luminescent materials. ${ }^{15-19}$

The usual wet-chemistry method for preparing supported metal clusters involves anchoring of well-defined precursors to a suitable support. ${ }^{20-21}$ The ligands are then removed by postsynthesis treatments, which usually results in clusters of high polydispersity. ${ }^{22-26}$ Soft landing of monodisperse metal clusters grown in a gas phase and sorted in size by mass spectrometry is an efficient method, however, it requires sophisticated equipment and the scaling up of the process is difficult. ${ }^{27,28}$

Here, we report the formation of sub-nanometer silver clusters with an enhanced narrow size distribution using uniform in size cages of FAU-type zeolite as a scaffold. A suspension of nanosized zeolite Na-X (FAU-type), denoted as ZX, was employed in this study. The extra small zeolite nanocrystals (10$30 \mathrm{~nm}$ ) were synthesized without organic template. The small size of zeolite scaffold is indispensable for the uniform incorporation and stabilization of the photoactive sites during the insitu synthesis as well as for the silver reduction, which requires a rapid ionic exchange ability. Sub-nanometer silver clusters in ZX (Ag@ZX-V) samples were prepared in two consecutive steps. The first step involves $i n$-situ incorporation of vanadate clusters (ZX-V), which are introduced to initiate the formation of $\mathrm{Ag}_{\mathrm{m}}{ }^{8+}$ (with $\mathrm{m}>\delta$ ) sub-nanometer clusters in zeolite cages. ${ }^{29}$ The second step comprises photocatalytic reduction of silver ions using a suspension of ZX-V to form Ag@ZX-V (SISection 2, Figure S1-S6). Ag@ZX-V(HT) prepared by a conventional hydrothermal method ${ }^{30}$ is used as a reference. The main objective of this study is to selectively generate uniform sub-nanometer silver clusters that exhibit photocatalytic activity under visible light and can be used as a catalyst for hydrogen production.

\section{Results and discussion}

The evolution of the absorbance spectra of $\mathrm{AgNO}_{3} / \mathrm{ZX}-\mathrm{V}$ suspensions as a function of exposure time to UV irradiation is reported in Figure 1. For comparison, the UV-visible spectrum of ZX suspension prepared under the same conditions and subjected to a longer irradiation time is also included. There is no reduction of silver in vanadium-free zeolite (ZX) suspension, 
while new UV-visible bands at 275, 300, 325, 371 and $414 \mathrm{~nm}$ appear after $30 \mathrm{~s}$ of UV irradiations of the vanadium-containing sample $(\mathrm{ZX}-\mathrm{V})$. The intensities of these bands increase with the irradiation time. In addition new bands at 432 and $562 \mathrm{~nm}$ attributed to the formation of silver nanoparticles with a particle size $>12 \mathrm{~nm}$ and $>20 \mathrm{~nm}$, respectively, appear in the spectrum after 30 seconds of treatment. $5,25,31-34$ The later bands originate from the formation of silver nanoparticles on the external surface of some of zeolite crystals (Figure S7). However, the major part of these particles is eliminated by a simple washing as demonstrate the UV-visible spectra of the washed samples (Figure S8). The bands between 275 and $380 \mathrm{~nm}$ are characteristic of the electronic transitions of reduced $\mathrm{Ag}$ species $\left(\mathrm{Ag}_{\mathrm{m}}{ }^{\delta+}\right)$ with sub-nanometer particles size. ${ }^{35-38}$ The presence of narrow UV bands at specific wavelength indicates that the silver clusters have well-defined size and charge. For the samples prepared by conventional hydrothermal process under similar reaction conditions, only a broad visible band at $430 \mathrm{~nm}$ in both ZX and ZX$\mathrm{V}$ samples is observed (Figure S9). This is a strong evidence for the formation of polydisperse silver particles with size larger than $12 \mathrm{~nm}$.

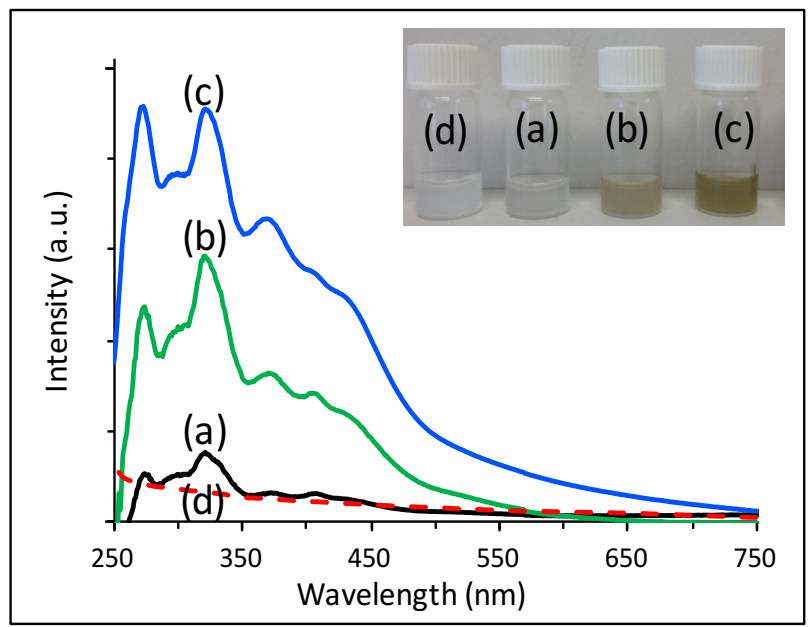

Figure 1. UV-visible spectra of ZX-V-1 suspensions after (a) 30 (b) 120 and (c) $300 \mathrm{~s}$ of UV irradiation in presence of $5 \times 10^{-3} \mathrm{M}$ of $\mathrm{AgNO}_{3}$. UV visible spectrum of $\mathrm{ZX}$ suspension after 10 minutes of $\mathrm{UV}$ irradiation in the presence of $5 \times 10^{-3} \mathrm{M}$ of $\mathrm{AgNO}_{3}$ (d). Inset: Optical images of the corresponding suspensions.
A direct evidence of the formation of sub-nanosized silver clusters in zeolite cages was obtained by HAADF-STEM analysis. The size $(10-30 \mathrm{~nm})$ and the morphology of ZX nanoparticles remain intact with respect to the untreated sample (Figure S1), with clearly expressed faceting with $<111>$ and $<100>$ planes (Figure 2a). Since HAADF-STEM contrast is proportional to atomic number $\left(\sim Z^{2}\right)$ and thickness, the heavier $\mathrm{Ag}$ $(Z=47)$ sub-nanoparticles appear as bright white dots within the pores. The dark spots correspond to surrounding ZX framework which is not clearly resolved due to the low density and large difference in atomic number between $\mathrm{Ag}$ and silica-alumina zeolite framework $\left(Z_{\mathrm{Si}}=14 ; \mathrm{Z}_{\mathrm{Al}}=13, \mathrm{Z}_{\mathrm{O}}=8\right)$. It should be noted that the framework of Ag-free ZX crystallites is visible in HAADFSTEM images (Figure S10). Despite the high sensitivity of the $\mathrm{Ag} @ \mathrm{ZX}-\mathrm{V}$ particles to the electron beam and tendency to agglomerate in larger Ag NPs (supporting information, Section III-A, Figure S11), it was possible to acquire almost an intact high resolution image along the [011] zone axis of a Ag@ZX$\mathrm{V}$ crystallite (Figure 2c) using low doses and weak e-beam conditions. ${ }^{39}$ The corresponding Fast Fourier Transform (FFT) pattern confirms the presence of Ag sub-nanoparticles within the pores of FAU-type structure. The Ag sub-nanoparticles appear in projection to have close to square shape with side lengths about $0.7 \mathrm{~nm}$, sharing common corners and forming checkerboard pattern reflecting the FAU structure symmetry. Their size is compatible with the diameter of the 12-member ring window of FAU super cage, as shown in Figure 2c insert, where the [011] FAU\&Ag structural model is laid over the experimental image. HAADF-STEM image and the corresponding structural model of FAU\&Ag projected on (112) plane are shown in Figure 2d. Large area of zeolite nanocrystals are almost completely filled with Ag (bright white contrast needles). The diameter of these needles is around $0.7 \mathrm{~nm}$ and perfectly fits with the entrance window diameter of the supercages. These needles can explain the visible absorbance of the silver sub-nanoparticles (Figure 1). However, the HAADF-STEM image and corresponding intensity plot profile reveals different degree of loading among the channels; some of them being completely free of Ag particles (Figure 2d). This result is attributed to a non-uniform distribution of photoactive vanadate clusters in the zeolite crystals and/or to an internal shielding of some of the crystals during the UV irradiation. 

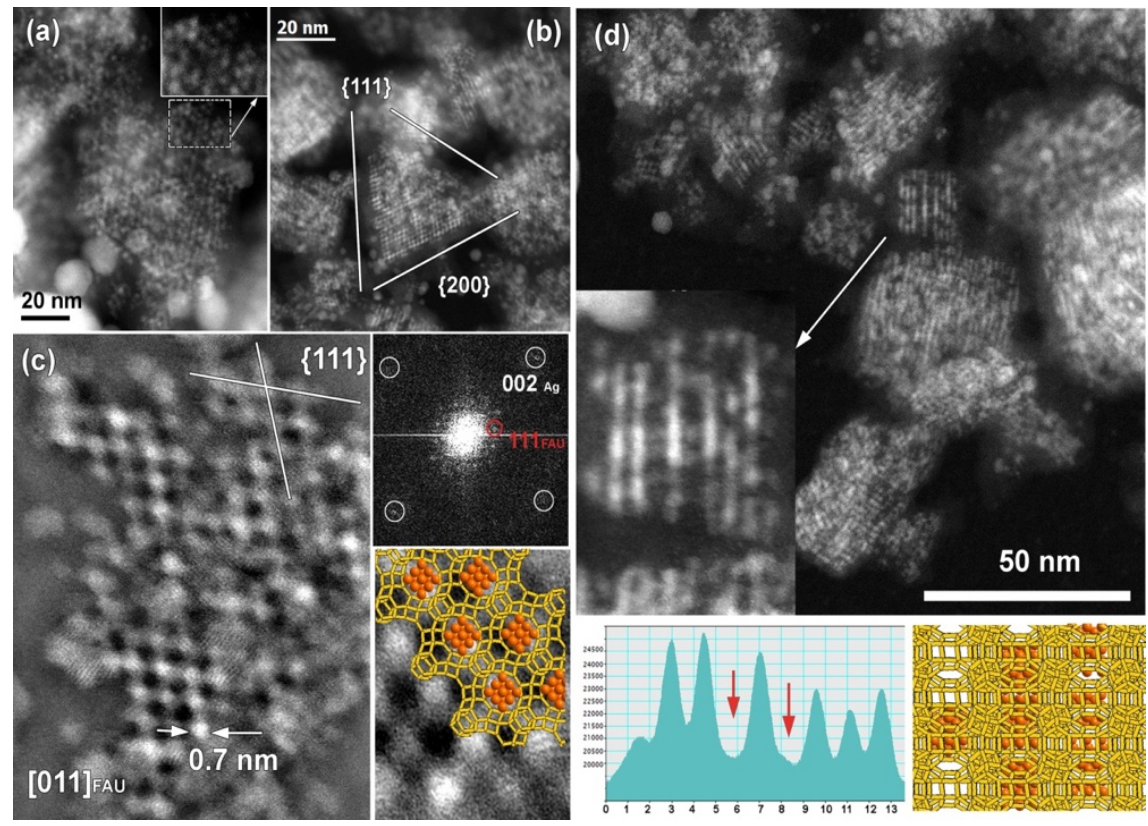

Figure 2. TEM analysis of the Ag@ZX-V sample: (a) Low magnification HAADF-STEM images of different Ag@ZX-V nanoparticles along [011 $]_{\mathrm{FAU}}$ Zone axis. Enlargement of the edge of Ag@ZX-V nanoparticle is given as inset (a) and shows well defined single Ag cluster with a characteristic size of around $0.7 \mathrm{~nm}$. (b) Triangle shaped Ag@ZX-V nanoparticle (outlined) imaged along [011 $]_{\text {FAU. }}$ (c) High resolution HAADF-STEM of Ag@ZX-V nanoparticle along [011 $]_{\text {FAU }}$ direction and corresponding FFT pattern confirm the presence of Ag nanoparticles within ZX-V material. Enlarged image with an overlaid structural model of Ag@ZX-V is given as inset. (d) HAADF-STEM image viewed along the channel close to [112 $]_{\text {FAU }}$ zone axis. Enlargement and corresponding intensity line profile show channels with different levels of Ag filling: from high (maximum intensity) to almost empty (marked with red arrows). Corresponding structural model is in the right bottom corner.

The evolution of faujasite crystals prior to $(\mathrm{ZX}-\mathrm{V})$ and after Ag loading (Ag@ZX-V) was studied by PXRD (Figure S12). For ZX-V, Rietveld refinement showed the following chemical formula $\mathrm{Na}_{82} \mathrm{Al}_{73} \mathrm{Si}_{119} \mathrm{O}_{384}\left(\mathrm{H}_{2} \mathrm{O}\right)_{139}$. The projection of the $\mathrm{ZX}-\mathrm{V}$ structure along the [011] axis is shown in Figure 3a. In this projection, the visible channels result from the alignment along [011] directions of the supercage "windows" and sodalite cages overlapping within the FAU framework. Both the sodalite (Figure 3c) and the supercage of faujasite (Figure 3e) are occupied by sodium cations and water molecules. The amount of sodium in sodalite and super cages are 21 and 55 out of $82 \mathrm{Na}^{+}$cations per formula unit, respectively. In contrast, the double six-member rings (D6R) are only occupied by $\mathrm{Na}^{+}$cations $\left(6\right.$ on $82 \mathrm{Na}^{+}$ cations). For $\mathrm{Ag} @ \mathrm{ZX}-\mathrm{V}$ the chemical formula calculated from the Rietveld refinement was $\mathrm{Ag}_{27} \mathrm{Na}_{55} \mathrm{Al}_{73} \mathrm{Si}_{119} \mathrm{O}_{384}\left(\mathrm{H}_{2} \mathrm{O}\right)_{120}$ with the stoichiometric sum of the $\mathrm{Ag}^{\delta+}$ and $\mathrm{Na}^{+}$cations equal to 82 , as previously observed for ZX-V.

The projection of $\mathrm{Ag} @ \mathrm{ZX}-\mathrm{V}$ structure along [110] axis is shown in Figure 2b. Notably, faujasite framework is preserved after the Ag loading. The comparison of the two structures, ZX-V and Ag@ZX-V, revealed that sodalite cages are occupied by $\mathrm{Na}^{+}$ions ( 32 out of $56 \mathrm{Na}^{+}$sites) and $\mathrm{H}_{2} \mathrm{O}$ molecules. After iexchange with $\mathrm{Ag}^{+}, \mathrm{Na}^{+}$located in proximity to the D6R is completely replaced by $\mathrm{Ag}_{\mathrm{m}}{ }^{\delta+}$ ions (Figure 3g). Only a few $\mathrm{Na}^{+}$ ions and water molecules remain in the supercage. $24 \mathrm{Na}^{+}$ cations are localized in the supercages of $\mathrm{Ag} @ \mathrm{ZX}-\mathrm{V}$, which is significantly lower than the $55 \mathrm{Na}^{+}$found in the supercages of $\mathrm{ZX}-\mathrm{V}$ before $\mathrm{Ag}$ loading. $\mathrm{Ag}_{\mathrm{m}}{ }^{\mathrm{S}}$ cations are also present at the border of the supercages in the vicinity of the 6 members ring. It should be noted that the positions of the Ag cations in $\mathrm{Ag} @ \mathrm{ZX}-\mathrm{V}$ are consistent with those observed in other silvercontaining faujasites. ${ }^{18,40-42}$ The Ag metal atoms that do not occupy zeolite crystallographic sites and form sub-nanometer silver clusters could not be localized from the PXRD data. However, difference Fourier maps were investigated during Rietveld refinement process and no residues attributable to Ag clusters were found. This suggests no ordering of silver clusters inside the 3D lattice of the faujasite. This result is fully consistent with the HAADF-STEM studies, which show sub-nanometer silver clusters randomly distributed inside the pores of the zeolite. Such a distribution produces only a weak diffuse scattering signal instead of XRD diffraction peaks. To underline the fact that after Ag exchange the supercage in $\mathrm{Ag} @ \mathrm{ZX}-\mathrm{V}$ are partially filled, the $\mathrm{Na}$ positions in the supercages occupied at $25 \%$ are drawn with a reduced radius (Figure 3b). This figure illustrates an average of ions/water distribution showing that a part of supercages is filled with silver atoms while the others remain occupied by $\mathrm{Na}^{+}$ions and water molecules. It should be noted that the characteristic XRD peaks of vanadate are not detected due to their low concentration $(<0.2$ wt. $\%) .{ }^{43}$ 

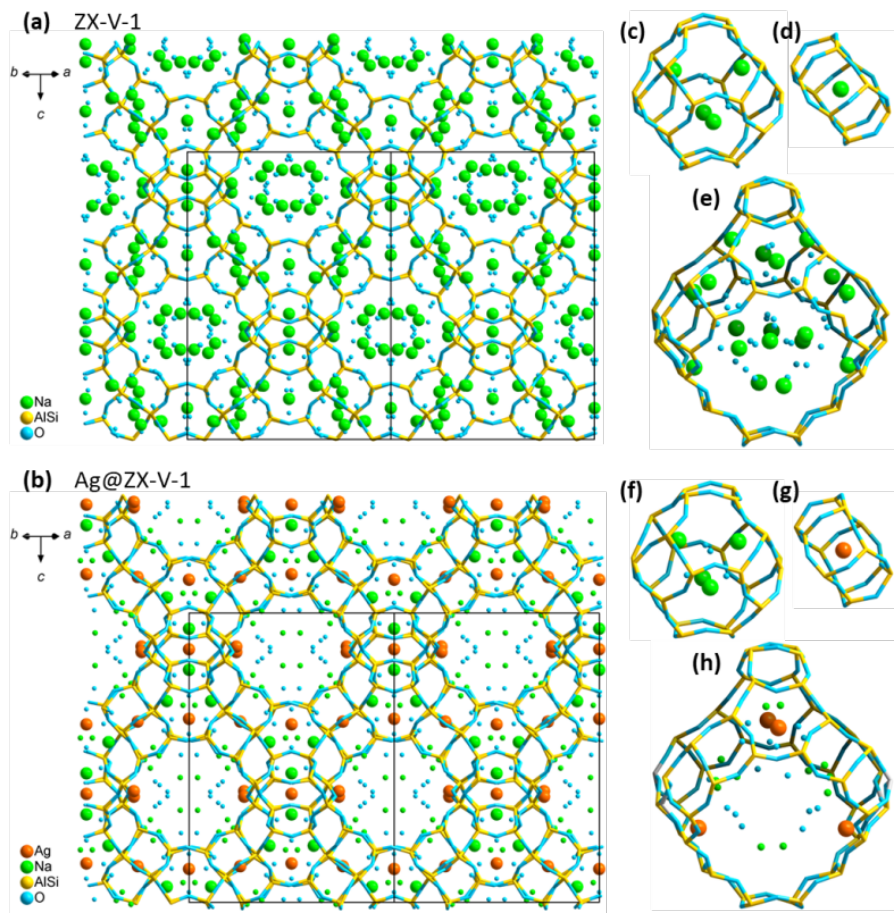

Figure 3. Schematic drawing of the faujasite structure along the [110] direction (a) before and (b) after Ag loading. (c) Sodalite cage, (d) D6R cage, (e) supercage of ZX-V before Ag loading. (f) Sodalite cage, (g) D6R cage, (h) Supercage of Ag@ZX-V after Ag loading.

FTIR spectroscopy of adsorbed CO provides valuable information on the oxidation state of silver nanoparticles. The FTIR spectra of CO adsorbed on Ag-exchanged ZX-V samples display broad absorption bands in the range $2170-2200 \mathrm{~cm}^{-1}$ corresponding to linear carbonyls $\mathrm{Ag}^{+}-\mathrm{CO}$ (Figure S13). ${ }^{44,45}$ The overlapping bands at 2180 and $2185 \mathrm{~cm}^{-1}$ are assigned to the $\mathrm{CO}$ adsorbed on $\mathrm{Ag}^{+}$ions located on the external surface and inside the pores, respectively. ${ }^{42}$ For Ag@ZX-V sample, the band at $2185 \mathrm{~cm}^{-1}$ is more intense pointing out that the Ag ions are mainly located inside the pores. In addition, this sample displays a broad band around $2140 \mathrm{~cm}^{-1}$ characteristic of adsorbed $\mathrm{CO}$ on reduced silver clusters. It is known that $\mathrm{CO}$ does not adsorb on the $\mathrm{Ag}^{0}$ at room temperature. ${ }^{46}$ Therefore, the low intensity of the band at $2140 \mathrm{~cm}^{-1}$ is rather induced by the weak adsorption ability of $\mathrm{Ag}_{\mathrm{m}}{ }^{\text {S+ }}$ clusters due to their low effective charge rather than their low concentration. It should be underlined that at room temperature no signal was observed in $\mathrm{Na}-\mathrm{ZX}$ and the ZX-V samples. This result points out that silver clusters possess partial positive charge (not completely metallic) and that they are accessible to CO (the pores are not completely filled).

The sub-nanometeric silver species represent the missing link between atomic and nanometer sized silver particles. The small size of these particles $(<1 \mathrm{~nm})$ render them photoluminescent with a molecular behavior. Their fluorescence emission is an undisputable evidence of this feature. The fluorescence spectra of the Ag@ZX-V suspension are reported in (Figure S14). An emission band centered at $550 \mathrm{~nm}$ can be clearly observed after the excitation of the sample at 270 or $320 \mathrm{~nm}$, but no fluorescence signal was observed for $\mathrm{Ag}^{+} / \mathrm{ZX}-\mathrm{V}$ suspension (Figure S15). This result confirms the molecular behavior of the subnanometer particles absorbing at 270 and $320 \mathrm{~nm}$. The excess of energy received by these particles is then released as radiative emission in visible region. In contrast, no emission is observed for the Ag@ZX-V suspension after excitation with 370 or $435 \mathrm{~nm}$. Therefore, the silver species that absorb at these wavelengths are nanoparticles with size larger than $2 \mathrm{~nm}$ (Figure 1). ${ }^{46}$ The absorption band at $>370 \mathrm{~nm}$ is attributed to needle silver nanoparticles connected through the window of supercages as demonstrated by the TEM analysis (Figure 2). The band at $435 \mathrm{~nm}$ originates from a few large particles attached to the external surface of zeolite crystals (Figure S16)

In order to shed light on the mechanism of silver cluster generation, series of experiments under different wavelength irradiations were performed. As mentioned, no silver photoreduction was observed in vanadium-free zeolite (ZX). This reveals the crucial role of vanadate species in the generation of Ag clusters. On the other hand, the concentration of vanadium is very low $(<0.2$ wt. $\%)$, which precludes the uniform and abundant presence of vanadium species in zeolite cages. The use of long wave ultraviolet light (UV-A or UV-B) did not result in $\mathrm{Ag}$ cluster formation. This is mainly due to the selective absorbance of vanadate species that takes place in the short-wave region of ultraviolet light (UV-C).$^{47}$ In the following experiment the sample was shortly (30 s) irradiated with polychromatic light (UV A - C), which 


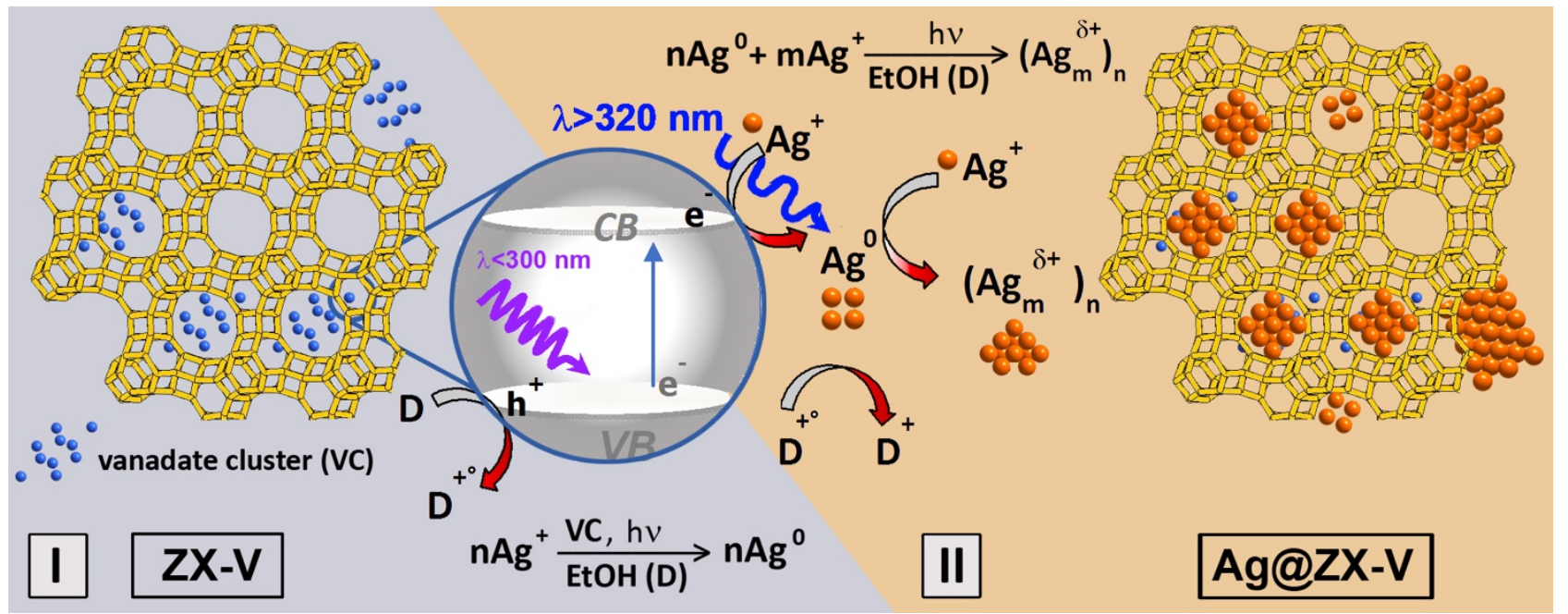

Scheme 1. Illustration of the photocatalytic process leading to the formation of silver clusters in the super cage of FAU-type zeolite: (I) silver photoreduction by excitation of the vanadate clusters (VC) with $\lambda<300$ nm (D); (II) photoreduction Ag $^{0}$ formed in the stage (I) by exicitation of silver clusters with $\lambda>320 \mathrm{~nm}$ (D).

irradiated that initiates the formation of silver clusters as revealed by the UV-visible spectrum of the suspension (Figure S17, a). The excitation of this sample with UV-B $(365 \mathrm{~nm})$ or visible $(>390 \mathrm{~nm})$ light, where only the silvers clusters absorb, led to an increase in the intensity of the characteristic bands of the sub-nanometers reduced silver clusters (Figure S17, b-c). These results unambiguously demonstrate that the vanadium species initiate the process of silver clusters formation. After this initial stage the obtained silver clusters generate new silver particles under UV-B-visible light excitation. The clusters grown until filling the zeolite cage and become immobile. The second stage of the process can be described as autocatalytic process where sliver clusters generation continues until exhausting the available silver pool. The self-production of $\mathrm{Ag}$ clusters explains their formation in neighboring supercages of FAU-type zeolite and the fact that large number of zeolite crystals exhibit rows of sub-nanometer Ag clusters (Scheme 1).

The photocatalytic activity of Ag@ZX-V was tested in the reforming of formic acid (FAc) to $\mathrm{H}_{2}$ and $\mathrm{CO}_{2}$ under visible and UV irradiations. This reaction offers an efficient route for hydrogen generation and thus attracts tremendous interest lately. ${ }^{48}$ However, the elaboration of an efficient catalyst remains a challenge. ${ }^{49,50}$ Namely, the dehydration reaction of FAc must be avoided in order to generate $\mathrm{H}_{2}$ without $\mathrm{CO}$ poisoning the catalyst in the fuel cells. ${ }^{51}$ During past decades, various catalysts combining noble metals and different supports have been explored to obtain a suitable catalyst for the selective dehydrogenation of FAc. ${ }^{52,53}$ The Ag@ZX-V has been tested in the photocatalytic reforming of formic acid in liquid phase. The reaction conditions are reported in the supplementary information. For comparison, silver exchanged $\mathrm{Ag}^{+} / \mathrm{ZX}-\mathrm{V}$ and $\mathrm{Ag} @ \mathrm{ZX}-\mathrm{V}(\mathrm{HT})$ prepared with by in-situ hydrothermal synthesis are used as references. The results are reported in (Figure 4). Ag@ZX-V exhibits 3 times higher activity than that of $\mathrm{Ag} @ \mathrm{ZX}-\mathrm{V}(\mathrm{HT})$ with a very high selectivity (more than 99\%) toward $\mathrm{H}_{2} / \mathrm{CO}_{2}$ formation. The silver content in $\mathrm{Ag} @ \mathrm{ZX}-$ $\mathrm{V}(\mathrm{HT})$ is substantially higher than in Ag@ZX-V. Nevertheless, the Ag@ZX-V shows impressively higher activity due to the uniform, sub-nanosized and stable silver particles generated by the new approach reported in the present study. There is no significant deactivation of the material after $16 \mathrm{~h}$ of reaction as proves the second cycle of the photocatalytic test (Figure S18). This demonstrates the high stability of the photocatalyst obtained by the new synthetic approach.

It should be noted that no significant activity forAg@ZX-V was observed under UV-light excitation (Figure S19). Therefore, the silver particles excited by UV-light release their gain of energy as radiative emission (fluorescence) while the excitation under visible light promotes the plasmonic/photocatalytic activity. The most plausible explanation of this phenomenon is the presence of needle-like silver providing the high activity under UV-light excitation, while the fluorescence emission is related with the isolated sub-nanometer clusters in the FAU cages. 


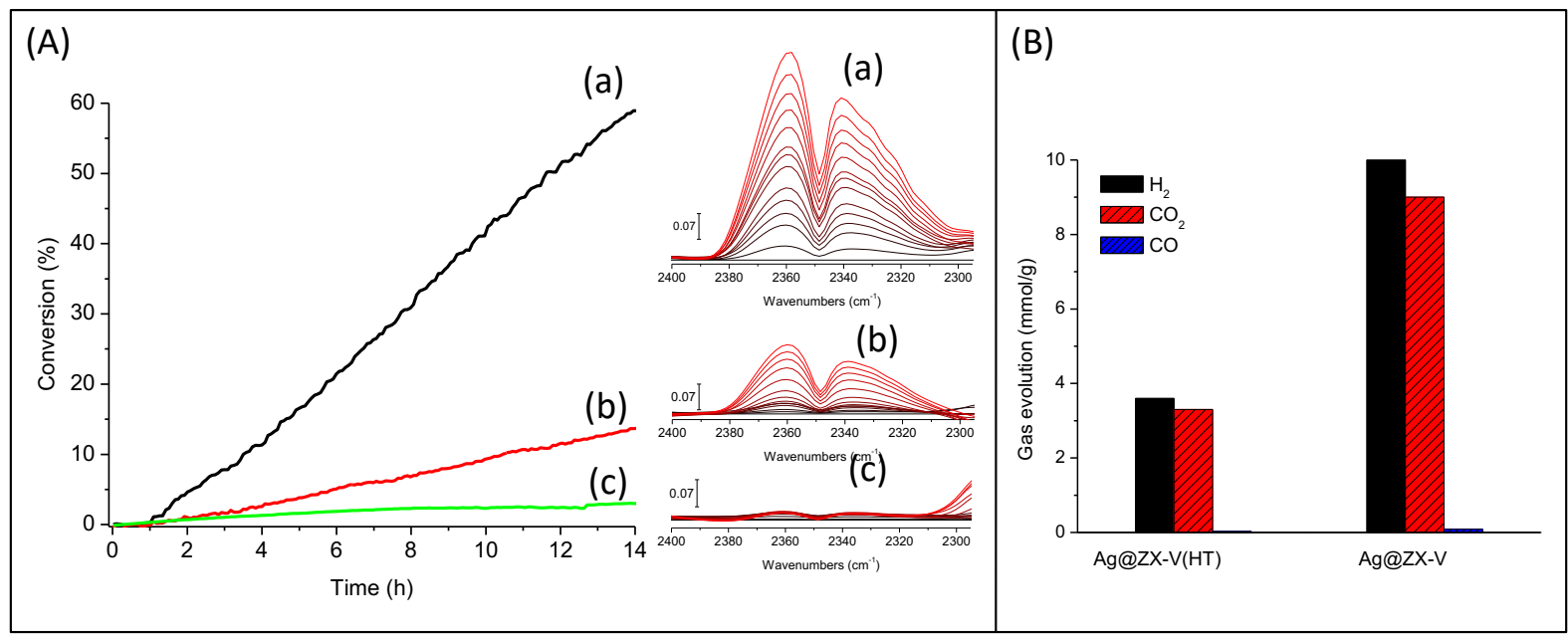

Figure 4. (A) Evolution of the formic acid conversion versus the visible irradiation $(\lambda>390 \mathrm{~nm})$ time over: (a) Ag@ZX-V, (b) Ag@ZX$\mathrm{V}(\mathrm{HT})$, and (c) ZX-V. Inset: figure correspond to the in-situ evolution of the $\mathrm{CO}_{2}$ IR band of headspace of the corresponding samples. (B) $\mathrm{H}_{2}, \mathrm{CO}_{2}$ and $\mathrm{CO}$ content determined after $5 \mathrm{~h}$ of visible-light irradiation of formic acid solution $\left(0.35 \mathrm{ml}\right.$ in $10 \mathrm{ml}$ of can; $\left.\mathrm{m}_{\text {catl }}=50 \mathrm{mg}\right)$ in the presence of $\mathrm{Ag} @ \mathrm{ZX}-\mathrm{V}(\mathrm{HT})$ and $\mathrm{Ag} @ \mathrm{ZX}-\mathrm{V}$ as photocatalysts.

\section{Conclusions}

In summary, a new approach for encapsulation of sub-nanometer silver clusters in the pores of zeolite nanoparticles was developed. The presence of vanadate clusters inside the zeolite pores, introduced by in-situ synthesis, is crucial for the formation of the first Ag clusters. Further, the self-photoreduction of silver is the dominant mechanism leading to extensive formation of sub-nanometer sized silver clusters encapsulated in zeolite cages. A characteristic feature of the process is the size uniformity of the generated sub-nanosized Ag clusters. The obtained materials exhibit a florescence emission and impressive photocatalytic activity in the reforming of formic acid (FAc) to $\mathrm{H}_{2}$ and $\mathrm{CO}_{2}$. The high performance of the new material in photocatalysis under visible light makes it a very promising candidate for renewable energy applications. In addition, the photoluminescent behavior makes the composite attractive for optical applications such as sensors for UV emissions as well as biomedical, electrocatalytic and imagery applications.

\section{ASSOCIATED CONTENT}

\section{Supporting Information}

The following data and results are available as Supporting information: experimental section including the characterization techniques and the synthesis procedures used in this work. Supplementary XRD, SEM, TEM, and IR results obtained for the different samples. Details of PXRD data and Rietveld refinements for ZX-V and Ag@ZX-V. This material is available free of charge via the Internet at http://pubs.acs.org.

\section{AUTHOR INFORMATION}

\section{Corresponding Author}

*mohamad.elroz@ensicaen.fr.

* valentin.valtchev@ensicaen.fr

\section{Author Contributions}

The manuscript was written through contributions of all authors. All authors have given approval to the final version of the manuscript. /

\section{Funding Sources}

No funds was used to support the research of the manuscript.

\section{ACKNOWLEDGMENT}

This work was supported by the European Union (Feder SIRCO project) and the Normandy Region (RHIN, RAPHYD project). The authors are grateful to Dr. Jaafar Elfallah and Dr. Sarah Komaty and Mr. Adrien Lanel for their help in performing SEM analyses, zeolite synthesis, and for creating the new in-situ IR reactor for liquid-gas photocatalysis, respectively.

\section{REFERENCES}

(1) Rycenga, M.; Cobley, C. M.; Zeng, J.; Li, W.; Moran, C. H.; Zhang, Q.; Qin, D.; Xia, Y. Controlling the Synthesis and Assembly of Silver Nanostructures for Plasmonic Applications. Chem. Rev. 2011, 111 (6), 3669-3712.

(2) Xu, Z.; Xiao, F.-S.; Purnell, S. K.; Alexeev, O.; Kawi, S.; Deutsch, S. E.; Gates, B. C. Size-Dependent Catalytic Activity of Supported Metal Clusters. Nature 1994, 372 (6504), 346-348.

(3) Corma, A.; Concepción, P.; Boronat, M.; Sabater, M. J.; Navas, J.; Yacaman, M. J.; Larios, E.; Posadas, A.; López-Quintela, M. A.; Buceta, D.; Mendoza, E.; Guilera, G.; Mayoral, A. Exceptional Oxidation Activity with Size-Controlled Supported Gold Clusters of Low Atomicity. Nat. Chem. 2013, 5 (9), 775-781.

(4) Desireddy, A.; Conn, B. E.; Guo, J.; Yoon, B.; Barnett, R. N.; Monahan, B. M.; Kirschbaum, K.; Griffith, W. P.; Whetten, R. L.; Landman, U.; Bigioni, T. P. Ultrastable Silver Nanoparticles. Nature 2013, 501 (7467), 399-402.

(5) Cuong, N. T.; Nguyen, H. M. T.; Nguyen, M. T. Theoretical Modeling of Optical Properties of Ag8 and Ag14 Silver Clusters Embedded in an LTA Sodalite Zeolite Cavity. Phys. Chem. Chem. Phys. 2013, 15 (37), 15404.

(6) Shang, L.; Dong, S. Silver Nanocluster-Based Fluorescent Sensors for Sensitive Detection of $\mathrm{Cu}(\mathrm{Ii})$. J. Mater. Chem. 2008, 18 (39), 4636.

(7) De Cremer, G.; Sels, B. F.; Hotta, J.; Roeffaers, M. B. J.; Bartholomeeusen, E.; Coutiño-Gonzalez, E.; Valtchev, V.; De Vos, D. E.; Vosch, T.; Hofkens, J. Optical Encoding of Silver Zeolite Microcarriers. Adv. Mater. 2010, 22 (9), 957-960. 
(8) Wang, H.-H.; Lin, C.-A. J.; Lee, C.-H.; Lin, Y.-C.; Tseng, Y.-M.; Hsieh, C.-L.; Chen, C.-H.; Tsai, C.-H.; Hsieh, C.-T.; Shen, J.L.; Chan, W.-H.; Chang, W. H., Yeh, H.-I. Fluorescent Gold Nanoclusters as a Biocompatible Marker for In Vitro and In Vivo Tracking of Endothelial Cells. ACS Nano 2011, 5 (6), 4337-4344.

(9) Gobin, A. M.; Lee, M. H.; Halas, N. J.; James, W. D.; Drezek, R. A.; West, J. L. Near-Infrared Resonant Nanoshells for Combined Optical Imaging and Photothermal Cancer Therapy. Nano Lett. 2007, 7 (7), 1929-1934.

(10) Royon, A.; Bourhis, K.; Bellec, M.; Papon, G.; Bousquet, B.; Deshayes, Y.; Cardinal, T.; Canioni, L. Silver Clusters Embedded in Glass as a Perennial High Capacity Optical Recording Medium. $A d v$. Mater. 2010, 22 (46), 5282-5286.

(11) Guo, C.; Irudayaraj, J. Fluorescent Ag Clusters via a ProteinDirected Approach as a Hg(II) Ion Sensor. Anal. Chem. 2011, 83 (8), 2883-2889.

(12) Patterson, H. H.; Gomez, R. S.; Lu, H.; Yson, R. L. Nanoclusters of Silver Doped in Zeolites as Photocatalysts. Catal. Today 2007, 120 (2), 168-173.

(13) Hutson, N. D.; Rege, S. U.; Yang, R. T. Mixed Cation Zeolites: $\mathrm{LiAg}-\mathrm{X}$ as a Superior Adsorbent for Air Separation. AIChE J 1999, 45 (4), 724-734.

(14) Seoung, D.; Lee, Y.; Cynn, H.; Park, C.; Choi, K.-Y.; Blom, D. A.; Evans, W. J.; Kao, C.-C.; Vogt, T.; Lee, Y. Irreversible Xenon Insertion into a Small-Pore Zeolite at Moderate Pressures and Temperatures. Nat. Chem. 2014, 6 (9), 835-839.

(15) Coutino-Gonzalez, E.; Roeffaers, M. B. J.; Dieu, B.; De Cremer, G.; Leyre, S.; Hanselaer, P.; Fyen, W.; Sels, B.; Hofkens, J. Determination and Optimization of the Luminescence External Quantum Efficiency of Silver-Clusters Zeolite Composites. J. Phys. Chem. C 2013, 117 (14), 6998-7004.

(16) Coutino-Gonzalez, E.; Baekelant, W.; Grandjean, D.; Roeffaers, M. B. J.; Fron, E.; Aghakhani, M. S.; Bovet, N.; Van der Auweraer, M.; Lievens, P.; Vosch, T.; Sels, B.; Hofkens, J. Thermally Activated LTA(Li)-Ag Zeolites with Water-Responsive Photoluminescence Properties. J. Mater. Chem. C 2015, 3 (45), 11857-11867.

(17) Fenwick, O.; Coutiño-Gonzalez, E.; Grandjean, D.; Baekelant, W.; Richard, F.; Bonacchi, S.; De Vos, D.; Lievens, P.; Roeffaers, M.; Hofkens, J.; Samorì, P. Tuning the Energetics and Tailoring the Optical Properties of Silver Clusters Confined in Zeolites. Nat. Mater. 2016, 15 (9), 1017-1022.

(18) Altantzis, T.; Coutino-Gonzalez, E.; Baekelant, W.; Martinez, G. T.; Abakumov, A. M.; Tendeloo, G. Van; Roeffaers, M. B. J.; Bals, S.; Hofkens, J. Direct Observation of Luminescent Silver Clusters Confined in Faujasite Zeolites. ACS Nano 2016, 10 (8), 7604-7611.

(19) Weckhuysen, B. M. Porous Materials: Zeolites Shine Bright. Nat. Mater. 2016, 15 (9), 933-934.

(20) Jia, C.-J.; Schüth, F. Colloidal Metal Nanoparticles as a Component of Designed Catalyst. Phys. Chem. Chem. Phys. 2011, 13 (7), 2457.

(21) Ledo-Suárez, A.; Rivas, J.; Rodríguez-Abreu, C. F.; Rodríguez, M. J.; Pastor, E.; Hernández-Creus, A.; Oseroff, S. B.; López-Quintela, M. A. Facile Synthesis of Stable Subnanosized Silver Clusters in Microemulsions. Angew. Chemie Int. Ed. 2007, 46 (46), $8823-8827$

(22) Turner, M.; Golovko, V. B.; Vaughan, O. P. H.; Abdulkin, P.; Berenguer-Murcia, A.; Tikhov, M. S.; Johnson, B. F. G.; Lambert, R. M. Selective Oxidation with Dioxygen by Gold Nanoparticle Catalysts Derived from 55-Atom Clusters. Nature 2008, 454 (7207), 981983.

(23) Liu, Y.; Tsunoyama, H.; Akita, T.; Tsukuda, T. Efficient and Selective Epoxidation of Styrene with TBHP Catalyzed by Au25clusters on Hydroxyapatite. Chem. Commun. 2010, 46 (4), 550-552.

(24) Xie, S.; Tsunoyama, H.; Kurashige, W.; Negishi, Y.; Tsukuda, T. Enhancement in Aerobic Alcohol Oxidation Catalysis of Au 25 Clusters by Single Pd Atom Doping. ACS Catal. 2012, 2 (7), 1519 1523.

(25) Zou, J.; Xu, Y.; Hou, B.; Wu, D.; Sun, Y. Controlled Growth of Silver Nanoparticles in a Hydrothermal Process. China Particuology 2007, 5 (3), 206-212.
(26) Wu, Y.; Wang, Z; Chen, S.; Wu, J.; Guo, X.; Liu, Z. OneStep Hydrothermal Synthesis of Silver Nanoparticles Loaded on NDoped Carbon and Application for Catalytic Reduction of 4-Nitrophenol. $R S C A d v$. 2015, 5 (106), 87151-87156.

(27) Lee, S.; Molina, L. M.; López, M. J.; Alonso, J. A.; Hammer, B.; Lee, B.; Seifert, S.; Winans, R. E.; Elam, J. W.; Pellin, M. J.; Vajda, S. Selective Propene Epoxidation on Immobilized Au 6-10 Clusters: The Effect of Hydrogen and Water on Activity and Selectivity. Angew. Chemie Int. Ed. 2009, 48 (8), 1467-1471.

(28) Schröder, F.; Esken, D.; Cokoja, M.; Berg, M. W. E. Van Den; Lebedev, O. I.; Tendeloo, G. Van; Walaszek, B.; Buntkowsky, G.; Limbach, H.; Chaudret, B.; Fischer, R. A. Ruthenium Nanoparticles inside Porous [ $\mathrm{Zn} 4 \mathrm{O}$ ( Bdc ) 3 ] by Hydrogenolysis of Adsorbed [ $\mathrm{Ru}$ ( Cod )( Cot )]: A Solid-State Reference System for Surfactant-Stabilized Ruthenium Colloids. J. Am. Chem. Soc. 2008, No. 12, 6119-6130.

(29) El-Roz, M.; Lakiss, L.; Vicente, A.; Bozhilov, K. N.; Thibault-Starzyk, F.; Valtchev, V. Ultra-Fast Framework Stabilization of Ge-Rich Zeolites by Low-Temperature Plasma Treatment. Chem. Sci. 2014, 5 (1), 68-80.

(30) Wang, J.; Li, J.; Guo, G.; Wang, Q.; Tang, J.; Zhao, Y.; Qin, H.; Wahafu, T.; Shen, H.; Liu, X.; Zhang, X. Silver-NanoparticlesModified Biomaterial Surface Resistant to Staphylococcus: New Insight into the Antimicrobial Action of Silver. Sci. Rep. 2016, 6 (1), 32699.

(31) Gurin, V. .; Petranovskii, V. .; Bogdanchikova, N. . Metal Clusters and Nanoparticles Assembled in Zeolites: An Example of Stable Materials with Controllable Particle Size. Mater. Sci. Eng. C 2002, 19 (1-2), 327-331.

(32) Elemike, E.; Onwudiwe, D.; Ekennia, A.; Sonde, C.; Ehiri, R. Green Synthesis of Ag/Ag2O Nanoparticles Using Aqueous Leaf Extract of Eupatorium Odoratum and Its Antimicrobial and Mosquito Larvicidal Activities. Molecules 2017, 22 (5), 674.

(33) Mock, J. J.; Barbic, M.; Smith, D. R.; Schultz, D. A.; Schultz, S. Shape Effects in Plasmon Resonance of Individual Colloidal Silver Nanoparticles. J. Chem. Phys. 2002, 116 (15), 6755-6759.

(34) Severance, M.; Dutta, P. K. Evolution of Silver Nanoparticles within an Aqueous Dispersion of Nanosized Zeolite Y: Mechanism and Applications. J. Phys. Chem. C 2014, 118 (49), 28580-28591.

(35) Mulvaney, P.; Henglein, A. Long-Lived Nonmetallic Silver Clusters in Aqueous Solution: A Pulse Radiolysis Study of Their Formation. J. Phys. Chem. 1990, 94 (10), 4182-4188.

(36) Treguer, M.; Rocco, F.; Lelong, G.; Le Nestour, A.; Cardinal, T.; Maali, A.; Lounis, B. Fluorescent Silver Oligomeric Clusters and Colloidal Particles. Solid State Sci. 2005, 7 (7), 812-818.

(37) Loginov, E.; Gomez, L. F.; Chiang, N.; Halder, A.; Guggemos, N.; Kresin, V. V.; Vilesov, A. F. Photoabsorption of AgN(N6-6000) Nanoclusters Formed in Helium Droplets: Transition from Compact to Multicenter Aggregation. Phys. Rev. Lett. 2011, 106 (23), 233401.

(38) Ozin, G. A.; Huber, H. Cryophotoclustering Techniques for Synthesizing Very Small, Naked Silver Clusters Agn of Known Size (Where $\mathrm{n}=2-5$ ). The Molecular Metal Cluster-Bulk Metal Particle Interface. Inorg. Chem. 1978, 17 (1), 155-163.

(39) Wiktor, C.; Meledina, M.; Turner, S.; Lebedev, O. I.; Fischer, R. A. Transmission Electron Microscopy on Metal-organic Frameworks - a Review. J. Mater. Chem. A 2017, 5 (29), 1496914989.

(40) Calestani, G.; Bacca, G.; Andreetti, G. D. Structural Study of Zeolite X Exchanged with 'f' Transition Elements. I. Crystal Structure of Reference Hydrated Na-X. Zeolites 1987, 7 (1), 54-58.

(41) Butikova, I. K.; Shepelev, Y. F.; Smolin, Y. I. Crystal-Structure of Ag-Ion Exchanged Modification of X-Zeolite. Kristallografiya 1989, 34 (5), 1136-1140.

(42) Gellens, L. R.; Mortier, W. J.; Uytterhoeven, J. B. Oxidation and Reduction of Silver in Zeolite Y: A Structural Study. Zeolites 1981, 1 (2), 85-90.

(43) El-Roz, M.; Lakiss, L.; Telegeiev, I.; Lebedev, O. I.; Bazin, P.; Vicente, A.; Fernandez, C.; Valtchev, V. High-Visible-Light Photoactivity of Plasma-Promoted Vanadium Clusters on Nanozeolites for Partial Photooxidation of Methanol. ACS Appl. Mater. Interfaces 2017, 9 (21), 17846-17855. 
(44) Pestryakov, A. N.; Davydov, A. A. Active Electronic States of Silver Catalysts for Methanol Selective Oxidation. Appl. Catal. A Gen. 1994, 120 (1), 7-15.

(45) Bechoux, K.; Marie, O.; Daturi, M.; Delahay, G.; Petitto, C.; Rousseau, S.; Blanchard, G. Infrared Evidence of Room Temperature Dissociative Adsorption of Carbon Monoxide over Ag/A12O3. Catal. Today 2012, 197 (1), 155-161.

(46) Kolobova, E.; Pestryakov, A.; Shemeryankina, A.; Kotolevich, Y.; Martynyuk, O.; Tiznado Vazquez, H. J.; Bogdanchikova, N. Formation of Silver Active States in Ag/ZSM-5 Catalysts for CO Oxidation. Fuel 2014, 138, 65-71.

(47) Zaarour, M.; El Roz, M.; Dong, B.; Retoux, R.; Aad, R.; Cardin, J.; Dufour, C.; Gourbilleau, F.; Gilson, J.-P.; Mintova, S. Photochemical Preparation of Silver Nanoparticles Supported on Zeolite Crystals. Langmuir 2014, 30 (21), 6250-6256.

(48) Celaje, J. J. A.; Lu, Z.; Kedzie, E. A.; Terrile, N. J.; Lo, J. N.; Williams, T. J. A Prolific Catalyst for Dehydrogenation of Neat Formic Acid. Nat. Commun. 2016, 7 (7), 11308.

(49) Jiang, Z.; Wan, W.; Li, H.; Yuan, S.; Zhao, H.; Wong, P. K. A Hierarchical Z-Scheme $\alpha-\mathrm{Fe}_{2} \mathrm{O}_{3} / \mathrm{g}-\mathrm{C}_{3} \mathrm{~N}_{4}$ Hybrid for Enhanced Photocatalytic $\mathrm{CO}_{2}$ Reduction. Adv. Mater. 2018, 1706108,1706108 .
(50) Zhou, M.; Wang, S.; Yang, P.; Huang, C.; Wang, X. Boron Carbon Nitride Semiconductors Decorated with CdS Nanoparticles for Photocatalytic Reduction of CO2. ACS Catal. 2018, 8, 4928-4936.

(51) Cheng, J.; Gu, X.; Liu, P.; Wang, T.; Su, H. Controlling Catalytic Dehydrogenation of Formic Acid over Low-Cost Transition Metal-Substituted AuPd Nanoparticles Immobilized by Functionalized Metal-organic Frameworks at Room Temperature. J. Mater. Chem. A 2016, 4, 16645-16652.

(52) Wen, M.; Mori, K.; Kuwahara, Y.; Yamashita, H. Plasmonic $\mathrm{Au} @$ Pd Nanoparticles Supported on a Basic Metal-Organic Framework: Synergic Boosting of $\mathrm{H} 2$ Production from Formic Acid. ACS Energy Lett. 2017, 2 (1), 1-7.

(53) Masuda, S.; Mori, K.; Futamura, Y.; Yamashita, H. PdAg Nanoparticles Supported on Functionalized Mesoporous Carbon: Promotional Effect of Surface Amine Groups in Reversible Hydrogen Delivery/Storage Mediated by Formic Acid/CO2. ACS Catal. 2018, 8 (3), 2277-2285. 
SYNOPSIS TOC

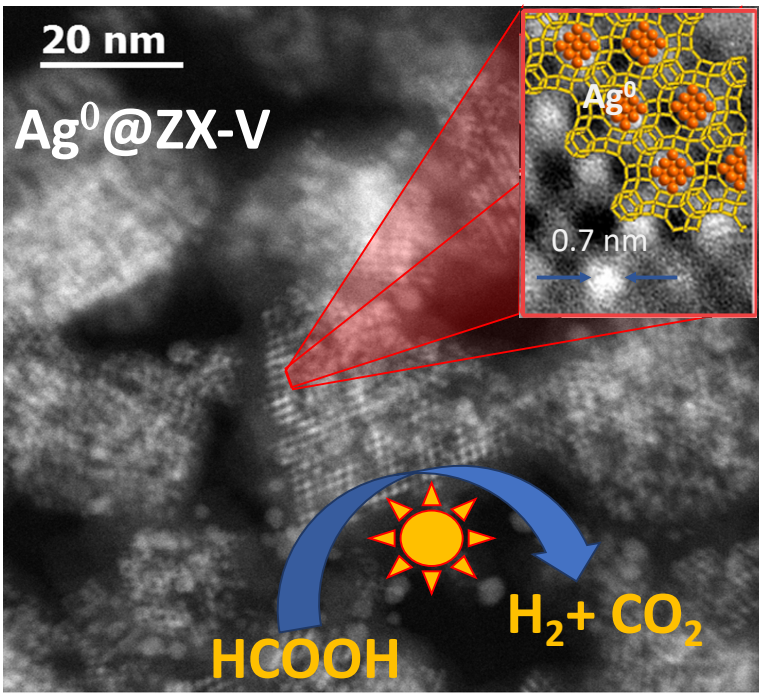

